\title{
BRIEF - SYNOPSIS OF THE CURRENT EVIDENCE ON THE RISK OF HIV TRANSMISSION
}

\author{
PAQUETTE D, DEMERS A, GALE-ROWE M, WONG T
}

KEY WORDS: HIV/AIDS, TRANSMISSION

\section{Structured abstract}

\section{BACKGROUND:}

Knowledge of the risk of HIV transmission has evolved over the past decade as evidence on the impact of biological and behavioural co-factors, such as viral load, has come to light. We undertook a comprehensive review of the evidence on the risk of HIV transmission.

\section{METHODS:}

A search was conducted for literature published between January 2001 and May 2012. The search focused on systematic, meta-analytic, and narrative reviews. For topics where no reviews existed, primary research studies were included.

\section{RESULTS:}

The risk estimates for the sexual transmission of HIV, per sex act, ranged from $0.5 \%$ to $3.38 \%$ (with mid-range estimates of $1.4 \%$ to $1.69 \%$ ) for receptive anal intercourse; $0.06 \%$ to $0.16 \%$ for insertive anal intercourse; $0.08 \%$ to $0.19 \%$ for receptive vaginal intercourse; and approximately $0.05 \%$ to $0.1 \%$ for insertive vaginal intercourse. For people who inject drugs, the risk of transmission from a contaminated needle, per injection, was estimated to be between $0.7 \%$ and $0.8 \%$. A number of factors impact the risk, including viral load, the presence of other sexually transmitted infections (STIs), and male circumcision.

\section{CONCLUSIONS:}

Within each route of transmission, estimates of the risk of transmission varied widely, likely due to the role of behavioural and biological co-factors. Viral load appears to be an important predictor of transmission, regardless of the route of transmission. However, the evidence indicates that viral load is not the only determinant and that certain co-factors play a role in increasing (e.g., STIs) or decreasing (e.g., male circumcision) the risk of transmission.

\section{Introduction}

Knowledge of the risk of HIV transmission and the co-factors that impact on risk, particularly viral load and its role in the transmission of HIV, is evolving. This information is valuable to health care professionals conducting risk assessments and counselling. It also provides a foundation for a better understanding of emerging HIV prevention approaches. In 2011, an estimated $84 \%$ of new infections were attributed to sexual transmission (47\% among men who have sex with men (MSM); $17 \%$ heterosexual/endemic exposure; and $20 \%$ heterosexual/non-endemic exposure), and $14 \%$ of new infections were among people who inject drugs (PWID) (1). 
Understanding the biological determinants of HIV transmission is essential for making predictions on the potential spread of HIV infection in a population, directing appropriate prevention strategies, and assessing the risk of infection to an individual who has been exposed to the virus. Our current knowledge of HIV transmission comes from various types of evidence, including animal studies, observational studies, randomized clinical trials (RCTs) and systematic reviews.

This is a summary of the current evidence on sexual transmission and transmission via injection and other drug use, the two most common routes of transmission in Canada. A review of the evidence on the risk of vertical transmission, in addition to a more detailed description of the risk associated with sexual transmission and transmission via drug use, can be found in the full document. (2).

\section{Methods}

We searched Scopus, Embase and CINAHL, and limited the search to articles published between 2001 and 2012 in English and French. Systematic reviews were the focus of the search. Where reviews did not exist, we included primary research studies. Key studies or commonly referenced publications outside of the time period were also included.

The following search terms were used: (HIV or "human immunodeficiency virus") and (transmission AND (probability OR rate OR risk)) OR (per AND contact) OR (per AND act) OR infectivity OR infectiousness OR transmissibility, along with key terms specific to each topic covered in this review.

\section{Results}

\section{SEXUAL TRANSMISSION}

Although there are challenges in quantifying risk by sex act, anal intercourse has consistently been shown to be a higher risk act than vaginal intercourse, which in turn is a higher risk act than oral intercourse. There is also a higher risk associated with receptive intercourse (both vaginal and anal) compared with insertive intercourse (Table 1).

The risk estimates for the transmission of HIV via anal intercourse, per sex act, ranges from $0.5 \%$ to $3.38 \%$ for receptive anal intercourse (3-6) and $0.06 \%$ to $0.16 \%$ for insertive anal intercourse (6-8). While most of these estimates are based on studies of MSM, the risk associated with anal intercourse appears to be similar within heterosexual populations (4).

The risk estimates of HIV transmission from receptive vaginal intercourse (male-to-female) range from $0.08 \%$ to $0.19 \%(5,6,9)$; and $0.05 \%$ to $0.1 \%$ for insertive vaginal intercourse (female-to-male) $(6,9)$.

A meta-analysis suggested a low but non-zero transmission probability from unprotected oral intercourse (whether penile-oral or vaginal-oral) (10). The risk of transmission to the receptive partner during oral intercourse increases with ejaculation and in the presence of oral ulcers and oropharyngeal sexually transmitted infections (STIs) $(10,11)$.

\section{VIRAL LOAD}

Plasma viral load is the strongest predictor of sexual transmission of HIV (12). For each 10 -fold increase in plasma viral load, the relative risk of transmission increases by 2.9 per sexual contact (9). The use of highly active antiretroviral therapy (HAART), which lowers viral load, was associated with a $96 \%$ reduction in the number of linked transmissions in an RCT of serodiscordant couples (most of which were heterosexual) (13). It is currently unclear whether there is a viral load threshold under which transmission no longer occurs. Also, little is known about the impact of viral load on the risk of transmission via anal intercourse. It is possible that the degree of risk reduction associated with HAART is not as great for this higher risk route of transmission. The results of ongoing studies (the PARTNER and Opposites Attract studies) will be useful in answering this question. 
Plasma viral load likely acts as a surrogate measure for HIV viral load in genital secretions (14), which plays a major role in sexual transmission (15-17). Concurrent STIs have been found to increase genital tract HIV shedding (15-17). Although HAART has been found to suppress HIV replication in the genital tract, non-adherence has been associated with persistent genital shedding of the virus (16). Further, shedding of the virus in the genital tract has been found even among those with undetectable plasma viral load $(18,19)$. The implications of this finding on the risk of transmission are currently unclear.

Primary (early) and late-stage HIV infections are marked by elevated viral load in plasma and in genital secretions $(20,21)$. In primary infections, this is due to the high degree of viral replication prior to the development of an immune response (20). Those in the primary stage of infection may also have other risk factors that led to the HIV infection (22). Late-stage infection, despite the elevated viral load, is likely to have a limited contribution to an HIV epidemic, since those with late-stage infection report less frequent sexual intercourse and fewer partners (21).

\section{SEXUALLY TRANSMITTED INFECTIONS (STIS)}

STIs have consistently been associated with increased susceptibility to HIV in observational studies (23). Several systematic reviews of high quality observational studies found that the presence of STIs increased susceptibility to HIV by a factor of 2 to 4 . This effect has been found for both men and women, specifically for herpes simplex virus type 2 (HSV-2); syphilis; gonorrhoea; chlamydia; trichomonas; and also exposure categorized as "any STI," "genital ulcer disease (GUD)," and "non-ulcerative STIs" (24-26). More recent observational studies have also associated the presence of human papillomavirus (HPV) with HIV acquisition among women, heterosexual men, and MSM $(27,28)$.

Studies indicate that STIs are also associated with increased infectiousness. Much of the evidence for this relationship comes from indirect approaches such as clinical studies that examine the possible biological mechanisms underlying the association. Few observational studies have examined this association (29); however, a systematic review of two studies found that genital ulcers and syphilis significantly increased the risk of HIV transmission 2- to 3-fold (24).

In contrast to the results of observational studies, the results of RCTs examining the impact of STI treatment on the risk of HIV transmission have been equivocal. The results of nine trials have been published to date: six assessed the effects of treating curable STIs, and three examined the impact of herpes suppressive therapy (30). The only trial to find a significant impact was the Mwanza (Tanzania) trial, which found a $40 \%$ reduction in HIV incidence following improved STI treatment services (31). The equivocal results may have been due to the type of epidemic within the community (30). In concentrated HIV epidemics, such as in Mwanza, treatable STIs may be an important co-factor in HIV transmission, which might not be the case in generalized epidemics found in the other trials $(30,32)$. Suboptimal adherence to HSV-suppressive therapy and a lack of power may have led to the inability of HSV treatment trials to demonstrate a significant effect $(23,30)$.

\section{INTACT FORESKIN IN MEN}

The three RCTs that studied the effect of male circumcision all found a $50 \%$ to $60 \%$ reduced risk of HIV acquisition (33). However, there is little epidemiological evidence to suggest that circumcision reduces the risk of transmission to female partners of circumcised men (34) or is effective in the prevention of HIV among MSM, except perhaps for men who report primarily an insertive role (35).

\section{TRANSMISSION VIA DRUG USE}

\section{USE OF INJECTION DRUGS}

The probability of HIV transmission per injection with a contaminated needle and syringe has been estimated indirectly using mathematical models, due to difficulties with accurately measuring the number of exposures (i.e., number of times a needle and syringe from an HIV-positive individual was shared) and other risk factors (e.g., viral load). Based on these models, the per injection probability of infection from a contaminated needle and syringe was found to be between $0.67 \%$ and $0.84 \%(36,37)$. Much like estimates of the risk from sexual transmission, such 
summary measures may be misleading as they do not convey the heterogeneity that exists in the risk of transmission per injection (37).

A number of observational studies have examined the risk of sharing, relative to not sharing, needles and syringes, where the HIV status of the injecting partner was unknown. Despite inconsistencies in how sharing needles and syringes was measured, studies have consistently found a positive relationship between the risk of HIV transmission, and needle and syringe sharing. In cohort studies conducted across Canada, those who shared needles and syringes were 1.5 to 5.9 times more likely to seroconvert $(38,39)$.

Studies suggest that sharing ancillary injecting equipment (e.g., water, cookers or filters) also increases the risk of HIV transmission. In a laboratory study, HIV DNA was detected in injection paraphernalia collected from shooting galleries in Miami (40) and observational studies have shown an epidemiological link between sharing drug preparation equipment and HIV transmission $(41,42)$.

\section{VIRAL LOAD}

There are few good quality studies on the association between viral load and the risk of transmission among PWID. For PWID on HAART, the degree of reduction in infectiousness is not known. Higher plasma viral loads have been found during outbreaks of HIV among PWID $(43,44)$. In addition, the community viral load of PWID was associated with HIV incidence in Vancouver (45). The community viral load is the mean or total of viral load measurements from a population (46). Community viral load is an aggregate measure, thus any association with this group-level measure is subject to ecological fallacy (i.e., an association between aggregate measures does not necessarily reflect a causal relationship at the individual level) (46).

\section{SEXUAL TRANSMISSION AMONG PWID}

Although the HIV epidemic among PWID is driven primarily by the sharing of injecting equipment, over the past decade the prevalence of syringe sharing has decreased. Studies have shown that after accounting for injecting behaviours, sexual transmission is becoming an important route of transmission in this group (47). HIV seroconversion among PWID has been independently associated with having an HIV-positive sexual partner and engaging in risky sex behaviours (e.g., multiple sexual partners, sex trade work, and inconsistent use of condoms) $(48,49)$.

\section{USE OF NON-INJECTION DRUGS}

Use of some non-injection drugs has been reported as an independent risk factor for HIV transmission. Crack smoking (in isolation) and amphetamine use have been identified as independent risk factors for HIV seropositivity, increasing the risk 2 - to 3 -fold $(50,51)$. Important limitations with these studies include their dependence on selfreported data and the difficulty of adjusting for confounding factors.

There is limited information on the mechanisms of HIV transmission solely through smoking or snorting. Sharing drug paraphernalia, like straws, banknotes, and crack pipes or stems, has been proposed as a transmission route. Blisters, sores, and cuts on the lips and in the mouths of crack smokers may facilitate oral transmission of HIV (5254), with the evidence supporting this causal relationship building but still sparse (11).

\section{Conclusion}

An individual's risk of HIV transmission is complex and depends on a number of behavioural and biological cofactors. It remains difficult to accurately quantify the risk of transmission associated with specific acts, however, in sexual transmission, unprotected receptive anal intercourse involves the greatest risk. Across the routes of transmission, plasma viral load appears to be an important predictor of transmission. However, while viral load is a key factor in whether HIV is transmitted, the evidence indicates that it is not the only determinant, and other cofactors play a role in increasing or decreasing the risk of transmission. This review of the evidence points to the 
growing and evolving nature of our knowledge of HIV transmission risk and the biological and behavioural co-factors that impact on that risk.

\section{Acknowledgements}

Many thanks to Chris Archibald, Christopher Boodram, Katherine Dinner, Katie Freer, Brian Gottheil, Ping Yan, and Ameeta Singh for their review and comments on the full document

\section{Conflict of interest statement}

There are no conflicts of interest to declare.

\section{Funding}

This work was supported by the Public Health Agency of Canada.

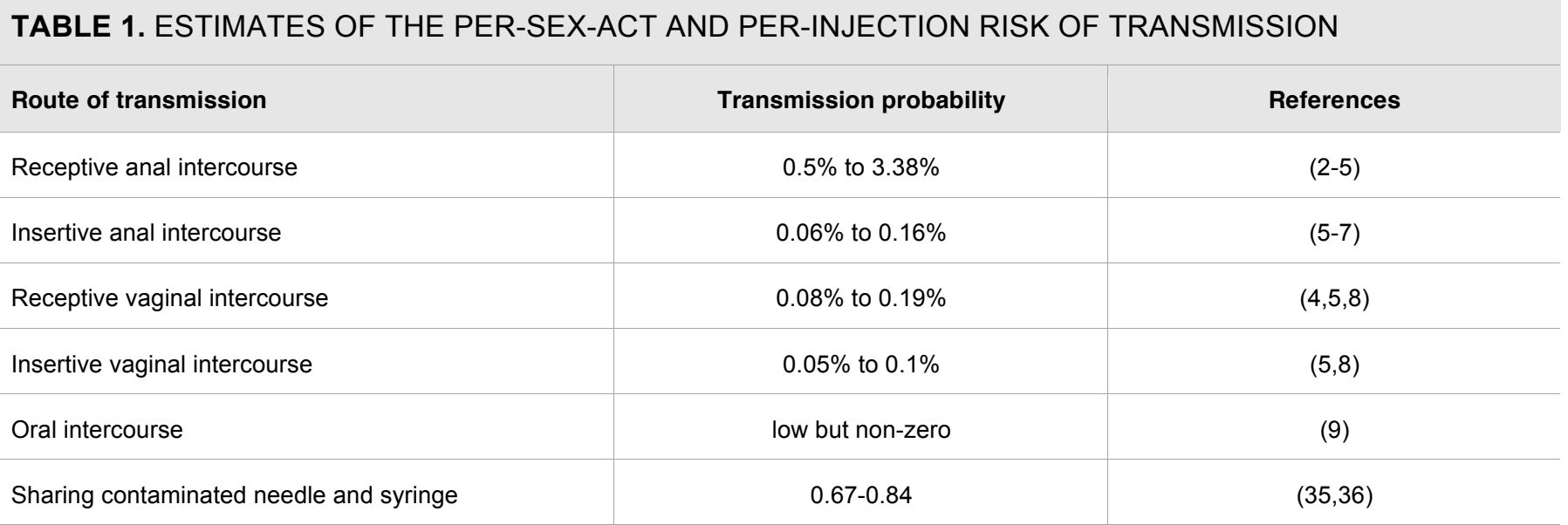

\section{References}

1. Public Health Agency of Canada. Summary: Estimates of HIV prevalence and incidence in Canada, 2011. Ottawa: Government of Canada 2012.

2. Public Health Agency of Canada. HIV transmission risk: A review of the evidence. Ottawa: Government of Canada; 2012. http://publications.gc.ca/site/eng/434865/publication.html

3. Powers KA, Poole C, Pettifor AE, Cohen MS. Rethinking the heterosexual infectivity of HIV-1: A systematic review and meta-analysis. Lancet Infect Dis. 2008;8(9):553-63.

4. Baggaley RF, White RG, Boily M-. HIV transmission risk through anal intercourse: Systematic review, meta-analysis and implications for HIV prevention. Int J Epidemiol. 2010;39(4):1048-63.

5. Boily M-, Baggaley RF, Wang L, Masse B, White RG, Hayes RJ, et al. Heterosexual risk of HIV-1 infection per sexual act: Systematic review and meta-analysis of observational studies. Lancet Infect Dis. 2009;9(2):118-29.

6. Fox J, White PJ, Weber J, Garnett GP, Ward H, Fidler S. Quantifying sexual exposure to HIV within an HIVserodiscordant relationship: Development of an algorithm. AIDS. 2011;25(8):1065-82. 
7. Vittinghoff E, Douglas J, Judson F, McKirnan D, Macqueen K, Buchbinder SR. Per-contact risk of human immunodeficiency virus transmission between male sexual partners. Am J Epidemiol. 1999;150(3):306-11.

8. Jin F, Jansson J, Law M, Prestage GP, Zablotska I, Imrie JCG, et al. Per-contact probability of HIV transmission in homosexual men in Sydney in the era of HAART. AIDS. 2010;24(6):907-13.

9. Hughes JP, Baeten JM, Lingappa JR, Magaret AS, Wald A, de Bruyn G, et al. Determinants of per-coital-act HIV-1 infectivity among African HIV-1-serodiscordant couples. J Infect Dis. 2012 February 01;205(3):358-65.

10. Baggaley RF, White RG, Boily MC. Systematic review of orogenital HIV-1 transmission probabilities. Int J Epidemiol. 2008;37(6):1255-65.

11. Campo J, Perea MA, Del Romero J, Cano J, Hernando V, Bascones A. Oral transmission of HIV, reality or fiction? an update. Oral Dis. 2006;12(3):219-28.

12. Fox J, Fidler S. Risk of HIV transmission in discordant partners. J HIV Ther. 2007;12(2):48-53.

13. Cohen MS, Chen YQ, McCauley M, Gamble T, Hosseinipour MC, Kumarasamy N, et al. Prevention of HIV-1 infection with early antiretroviral therapy. N Engl J Med. 2011;365(6):493-505.

14. Cohen MS, Gay C, Kashuba AD, Blower S, Paxton L. Narrative review: Antiretroviral therapy to prevent the sexual transmission of HIV-1. Ann Intern Med. 2007;146(8):591-601.

15. Anderson BL, Cu-Uvin S. Determinants of HIV shedding in the lower genital tract of women. Curr Infect Dis Rep. 2008;10(6):505-11.

16. Kalichman SC, Di Berto G, Eaton L. Human immunodeficiency virus viral load in blood plasma and semen: Review and implications of empirical findings. Sex Transm Dis. 2008;35(1):55-60.

17. Spinillo A, Gardella B, Zanchi S, Roccio M, Preti E. Determinants of genital shedding of human immunodeficiency virus: A review. Curr Women's Health Rev. 2008;4(2):118-23.

18. Politch JA, Mayer KH, Welles SL, O'brien WX, Xu C, Bowman FP, et al. Highly active antiretroviral therapy does not completely suppress HIV in semen of sexually active HIV-infected men who have sex with men. AIDS. 2012 Mar 23.

19. Cu-Uvin S, DeLong AK, Venkatesh KK, Hogan JW, Ingersoll J, Kurpewski J, et al. Genital tract HIV-1 RNA shedding among women with below detectable plasma viral load. AIDS. 2010;24(16):2489-97.

20. Miller WC, Rosenberg NE, Rutstein SE, Powers KA. Role of acute and early HIV infection in the sexual transmission of HIV. Curr Opin HIV AIDS. 2010;5(4):277-82.

21. Wawer MJ, Gray RH, Sewankambo NK, Serwadda D, Li X, Laeyendecker O, et al. Rates of HIV-1 transmission per coital act, by stage of HIV-1 infection, in Rakai, Uganda. J Infect Dis. 2005;191(9):1403-9.

22. Dosekun O, Fox J. An overview of the relative risks of different sexual behaviours on HIV transmission. Current Opinion in HIV and AIDS. 2010;5(4):291-7.

23. Ward H, Rönn M. Contribution of sexually transmitted infections to the sexual transmission of HIV. Current Opinion in HIV and AIDS. 2010;5(4):305-10.

24. Røttingen J-, Cameron WD, Garnett GP. A systematic review of the epidemiologic interactions between classic sexually transmitted diseases and HIV: How much really is known? Sex Transm Dis. 2001;28(10):579-97.

25. Freeman EE, Weiss HA, Glynn JR, Cross PL, Whitworth JA, Hayes RJ. Herpes simplex virus 2 infection increases HIV acquisition in men and women: Systematic review and meta-analysis of longitudinal studies. AIDS. 2006;20(1):73-83.

26. Sexton J, Garnett G, Rottingen JA-. Metaanalysis and metaregression in interpreting study variability in the impact of sexually transmitted diseases on susceptibility to HIV infection. Sex Transm Dis. 2005;32(6):351-7.

27. Auvert B, Marais D, Lissouba P, Zarca K, Ramjee G, Williamson AL-. High-risk human papillomavirus is associated with HIV acquisition among South African female sex workers. Infect Dis Obstet Gynecol. 2011;2011:692012.

28. Smith JS, Moses S, Hudgens MG, Parker CB, Agot K, Maclean I, et al. Increased risk of HIV acquisition among Kenyan men with human papillomavirus infection. J Infect Dis. 2010;201(11):1677-85. 
29. Galvin SR, Cohen MS. The role of sexually transmitted diseases in HIV transmission. Nat Rev Microbiol. 2004;2(1):33-42.

30. Hayes R, Watson-Jones D, Celum C, van de Wijgert J, Wasserheit J. Treatment of sexually transmitted infections for HIV prevention: End of the road or new beginning? AIDS. 2010;24(SUPPL. 4):S15-26.

31. Grosskurth H, Mosha F, Todd J, Mwijarubi E, Klokke A, Senkoro K, et al. Impact of improved treatment of sexually transmitted diseases on HIV infection in rural Tanzania: Randomised controlled trial. Lancet. 1995;346(8974):530-6.

32. Barnabas RV, Wasserheit JN. Riddle of the sphinx revisited: The role of STDs in HIV prevention. Sex Transm Dis. 2009;36(6):365-7.

33. Siegfried N, Muller M, Deeks JJ, Volmink J. Male circumcision for prevention of heterosexual acquisition of HIV in men. Cochrane Database Syst Rev. 2009(2).

34. Weiss HA, Hankins CA, Dickson K. Male circumcision and risk of HIV infection in women: A systematic review and metaanalysis. Lancet Infect Dis. 2009;9(11):669-77.

35. Millett GA, Flores SA, Marks G, Reed JB, Herbst JH. Circumcision status and risk of HIV and sexually transmitted infections among men who have sex with men: A meta-analysis. JAMA. 2008;300(14):1674-84.

36. Kaplan EH, Heimer R. A model-based estimate of HIV infectivity via needle sharing. J Acquir Immune Defic Syndr. 1992;5(11):1116-8.

37. Hudgens MG, Longini Jr. IM, Halloran ME, Choopanya K, Vanichseni S, Kitayaporn D, et al. Estimating the transmission probability of human immunodeficiency virus in injecting drug users in Thailand. Appl Statist. 2001;50(1):1-14.

38. Miller CL, Kerr T, Frankish JC, Spittal PM, Li K, Schechter MT, et al. Binge drug use independently predicts HIV seroconversion among injection drug users: Implications for public health strategies. Subst Use Misuse. 2006;41(2):199210.

39. Bruneau, J., Daniel, M., Abrahamowicz, M., Zang, G., Lamothe, F., Vincelette,J. Trends in human immunodeficiency virus incidence and risk behavior among injection drug users in Montreal, Canada: A 16-year longitudinal study. Am J Epidemiol. 2011;173(9):1049-58.

40. Shah SM, Shapshak P, Rivers JE, Stewart RV, Weatherby NL, Xin KQ, et al. Detection of HIV-1 DNA in needle/syringes, paraphernalia, and washes from shooting galleries in Miami: A preliminary laboratory report. J Acquir Immune Defic Syndr Hum Retrovirol. 1996 Mar 1;11(3):301-6.

41. Brogly SB, Bruneau J, Vincelette J, Lamothe F, Franco EL. Risk behaviour change and HIV infection among injection drug users in Montreal. AIDS. 2000 Nov 10;14(16):2575-82.

42. Zhang Y, Shan H, Trizzino J, Ruan Y, Beauchamp G, Mâsse B, et al. Demographic characteristics and risk behaviors associated with HIV positive injecting drug users in Xinjiang, China. J Infect. 2007;54(3):285-90.

43. Hu DJ, Subbarao S, Vanichseni S, Mock PA, van Griensven F, Nelson R, et al. Higher viral loads and other risk factors associated with HIV-1 seroconversion during a period of high incidence among injection drug users in Bangkok. J Acquir Immune Defic Syndr. 2002 Jun 1;30(2):240-7.

44. Kivelä PS, Krol A, Salminen MO, Geskus RB, Suni JI, Anttila V-, et al. High plasma HIV load in the CRF01-AE outbreak among injecting drug users in Finland. Scand J Infect Dis. 2005;37(4):276-83.

45. Wood E, Kerr T, Marshall BD, Li K, Zhang R, Hogg RS, et al. Longitudinal community plasma HIV-1 RNA concentrations and incidence of HIV-1 among injecting drug users: Prospective cohort study. BMJ. 2009;338.

46. Castel AD, Befus M, Willis S, Griffin A, West T, Hader S, et al. Use of the community viral load as a population-based biomarker of HIV burden. AIDS. 2012 Jan 28;26(3):345-53.

47. Des Jarlais DC, Arasteh K, McKnight C, Hagan H, Perlman DC, Semaan S. Associations between herpes simplex virus type 2 and HCV with HIV among injecting drug users in New York City: The current importance of sexual transmission of HIV. Am J Public Health. 2011;101(7):1277-83.

48. Strathdee SA, Galai N, Safaiean M, Celentano DD, Vlahov D, Johnson L, et al. Sex differences in risk factors for HIV seroconversion among injection drug users: A 10-year perspective. Arch Intern Med. 2001 May 28;161(10):1281-8. 
49. Bacon O, Lum P, Hahn J, Evans J, Davidson P, Moss A, et al. Commercial sex work and risk of HIV infection among young drug-injecting men who have sex with men in San Francisco. Sex Transm Dis. 2006;33(4):228-34.

50. McCoy CB, Lai S, Metsch LR, Messiah SE, Zhao W. Injection drug use and crack cocaine smoking: Independent and dual risk behaviors for HIV infection. Ann Epidemiol. 2004 Sep;14(8):535-42.

51. DeBeck K, Kerr T, Li K, Fischer B, Buxton J, Montaner J, et al. Smoking of crack cocaine as a risk factor for HIV infection among people who use injection drugs. CMAJ. 2009;181(9):585-9.

52. Faruque S, Edlin BR, McCoy CB, Word CO, Larsen SA, Schmid DS, et al. Crack cocaine smoking and oral sores in three inner-city neighborhoods. J Acquir Immune Defic Syndr Hum Retrovirol. 1996 Sep;13(1):87-92.

53. Porter J, Bonilla L, Drucker E. Methods of smoking crack as a potential risk factor for HIV infection: Crack smokers' perception and behavior. Contemp Drug Probl. 1997;24:319-48.

54. Porter J, Bonilla L. Crack users' cracked lips: An additional HIV risk factor. Am J Public Health. 1993 Oct;83(10):1490-1. 